EGU21-10016

https://doi.org/10.5194/egusphere-egu21-10016

EGU General Assembly 2021

(c) Author(s) 2021. This work is distributed under

the Creative Commons Attribution 4.0 License.

\title{
Inferring London's Methane Emissions from Atmospheric Measurements
}

Daniel Hoare ${ }^{1}$, Rod L Jones ${ }^{2}$, Shiwei Fan ${ }^{2}$, Neil Harris ${ }^{3}$, Valerio Ferracci ${ }^{3}$, David Carruthers ${ }^{4}$, Amy Stidworthy ${ }^{4}$, Ella Forsyth ${ }^{4}$, and Matt Rigby ${ }^{1}$

${ }^{1}$ University of Bristol, Bristol, United Kingdom

${ }^{2}$ University of Cambridge, Cambridge, United Kingdom

${ }^{3}$ Cranfield University, Cranfield, United Kingdom

${ }^{4}$ Cambridge Environmental Research Consultants, Cambridge, United kingdom

Major cities such as London are increasingly becoming targets for reducing greenhouse gas emissions by policy makers. This is due in part to their higher rate of emissions compared to more rural areas, but also due to the political powers of city level government. To ensure that emission reduction policies are successful, policy makers require accurate knowledge of how emissions change over time.

The London Greenhouse Gas Project aims to provide top-down emission estimates for London, adding a London measurement network to expand upon the UK's existing national top-down measurement infrastructure. The national network has proved useful in contributing to the UK's national emission reports, and the new local network will provide useful data targeted to London's policy makers.

A series of in-situ atmospheric concentration instruments are being installed across the city and will be used to estimate London's emissions of methane initially, with carbon dioxide emissions to follow. A medium-density urban network provides challenges in instrument calibration and siting, as well as the development of new modelling approaches to capture the urban environment and link the measurements to policy-relevant emissions estimates. There are also opportunities to link with remote observations of London, including satellite and ground-based FTIR instruments. We present considerations of setting up the new network, and results from the initial instrument installation and model development. 